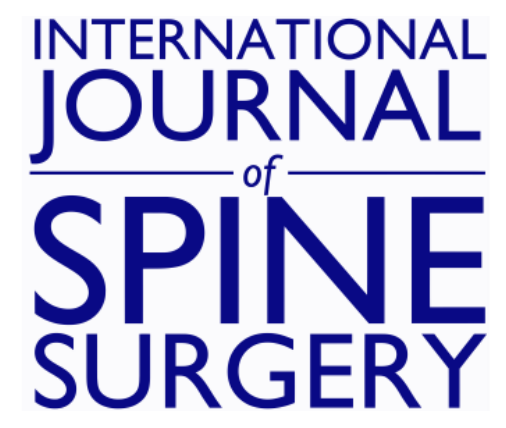

\title{
Biomechanical Comparison of Robotically Applied Pure Moment, Ideal Follower Load, and Novel Trunk Weight Loading Protocols on L4-L5 Cadaveric Segments during Flexion-Extension
}

Charles R. Bennett, Denis J. DiAngelo and Brian P. Kelly

Int J Spine Surg 2015, 9 ()

doi: https://doi.org/10.14444/2033

http://ijssurgery.com/content/9/33

This information is current as of April 26, 2023.

Email Alerts Receive free email-alerts when new articles cite this article. Sign up at:

http://ijssurgery.com/alerts

The International Journal of Sphine Surgerbittp://ijssurgery.com/ by guest on April 26, 2 2397 Waterbury Circle, Suite 1,

Aurora, IL 60504, Phone: +1-630-375-1432

(C) 2015 ISASS. All Rights Reserved. 


\section{Biomechanical Comparison of Robotically Applied Pure Moment, Ideal Follower Load, and Novel Trunk Weight Loading Protocols on L4-L5 Cadaveric Segments during Flexion-Extension}

Charles R. Bennett, MS, ${ }^{1}$ Denis J. DiAngelo, PhD, ${ }^{1}$ Brian P. Kelly, PhD ${ }^{2}$

${ }^{1}$ Department of Orthopedic Surgery and Biomedical Engineering, University of Tennessee Health Science Center, Memphis TN, ${ }^{2}$ Division of Neurological Surgery, Barrow Neurological Institute, Phoenix, $A Z$

\section{Abstract}

\section{Background}

Extremely few in-vitro biomechanical studies have incorporated shear loads leaving a gap for investigation, especially when applied in combination with compression and bending under dynamic conditions. The objective of this study was to biomechanically compare sagittal plane application of two standard protocols, pure moment (PM) and follower load (FL), with a novel trunk weight (TW) loading protocol designed to induce shear in combination with compression and dynamic bending in a neutrally potted human cadaveric L4-L5 motion segment unit (MSU) model. A secondary objective and novelty of the current study was the application of all three protocols within the same testing system serving to reduce artifacts due to testing system variability.

\section{Methods}

Six L4-L5 segments were tested in a Cartesian load controlled system in flexion-extension to 8Nm under PM, simulated ideal $400 \mathrm{~N} \mathrm{FL}$, and vertically oriented $400 \mathrm{~N}$ TW loading protocols. Comparison metrics used were rotational range of motion (RROM), flexibility, neutral zone (NZ) range of motion, and L4 vertebral body displacements.

Results

Significant differences in vertebral body translations were observed with different initial force applications but not with subsequent bending moment application. Significant reductions were observed in combined flexion-extension RROM, in flexibility during extension, and in NZ region flexibility with the TW loading protocol as compared to PM loading. Neutral zone ranges of motion were not different between all protocols.

\section{Conclusions}

The combined compression and shear forces applied across the spinal joint in the trunk weight protocol may have a small but significantly increased stabilizing effect on segment flexibility and kinematics during sagittal plane flexion and extension.

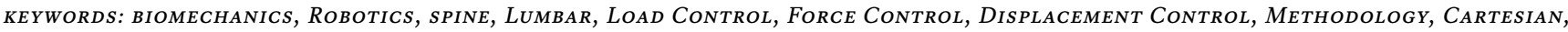
Mechanical testing, Six Degrees of Freedom, Follower Load, Trunk Weight, Pure Moment, Protocol Comparison

VOLUME 9 ARTICLE 33 - BIOMECHANICS SPECIAL ISSUE DOI: 10.14444/2033

\section{Introduction}

Standard protocols for in-vitro spine testing include pure moment (PM) and follower load (FL) protocols. ${ }^{1,2}$ The PM protocol prescribes application of a single pure bending moment to a test specimen typically within anatomical planes. The FL protocol applies a constant compressive force normal to the midline of the intervertebral disc in combination with sagittal plane pure bending. In addition to these loads it has been reported that in the in-vivo environment the spine may be subjected to substantial shear forces. ${ }^{3-5}$ In a standing upright neutral posture shear forces exist at the lower lumbar levels owing to gravitational trunk weight loading applied across the inclined functional spinal joint levels. Extremely few 
in-vitro biomechanical studies have incorporated shear loads ${ }^{6-8}$ leaving a gap for investigation especially when applied in combination with compression and bending under dynamic conditions.

With regard to understanding the extent to which different load conditions influence spinal stability and motion, a potentially important confounding factor is the wide variety of different testing techniques used. Various mechanisms have been used to apply prescribed loads including hanging dead weights, ${ }^{1,9}$ cable and pulley systems, ${ }^{10-12}$ actuation systems in combination with passive linkages, ${ }^{13-15}$ fully actuated systems,${ }^{16}$ and multi-axial robotically coordinated hexapod, ${ }^{17,18}$ multi-revolute, ${ }^{19-21}$ and orthogonal gantry, ${ }^{22,23}$ testing systems. While comparisons of different spine conditions are common in the literature, comparisons of different testing protocols and/or testing systems are almost nonexistent. ${ }^{24,25}$ Clinicians and researchers are left to compare and interpret data from different systems with dissimilar testing protocols that may result in contradictions or spurious comparisons. ${ }^{1,25-30}$

The objective of this study was to biomechanically compare sagittal plane application of two standard protocols, PM and the ideal FL, with a novel trunk weight (TW) loading protocol designed to induce shear in combination with compression and dynamic bending in a neutrally potted human cadaveric L4-L5 motion segment unit (MSU) model. Comparison metrics used were rotational range of motion (RROM), flexibility, neutral zone range of motion (NZ-ROM), and vertebral body translations. A secondary objective and novelty of the current study was the application of all three protocols within a previously developed Cartesian load-controlled testing system, serving to reduce artifacts derived from testing system variability.

\section{Materials and Methods}

Specimen Preparation

Six fresh-frozen human cadaveric L1-S1 lumbar MSUs (male, mean age 44 years (SD 8.9)) were radiographically pre-screened for degenerative changes, harvested, and cleaned of excessive tissue. L4-L5 segments were sectioned and potted in bismuth alloy

$\left(\right.$ Cerrobend $\left.^{\mathrm{TM}}\right)$ in specimen-specific, natural lordotic alignment referenced to the assumed horizontal cranial endplate of L1, and frozen until tested. This procedure was initially chosen so that shear forces induced in the TW protocol would correlate with each specimen's estimated natural alignment and thus be physiologically representative of the in-vivo case for each.

Each potted specimen was analyzed to determine the midline of the disc. Corners of the cranial and caudal endplates were located (Figure 1) and cross-disc lines drawn connecting the two anterior and two posterior points. Cross-disc line midpoints were connected with a line that defined the midline of the intervertebral disc. The angle between the disc midline and the testing system Global Coordinate System (GCS) horizontal was defined as $\beta$. The midline and its normal formed a mobile 2D disc coordinate system (DCS) that rotated with the disc midline during testing.

\section{Real-Time Loading Protocols}

A Cartesian load controlled testing system (CLTS) was used in the current study with previously report-

Corner of endplate

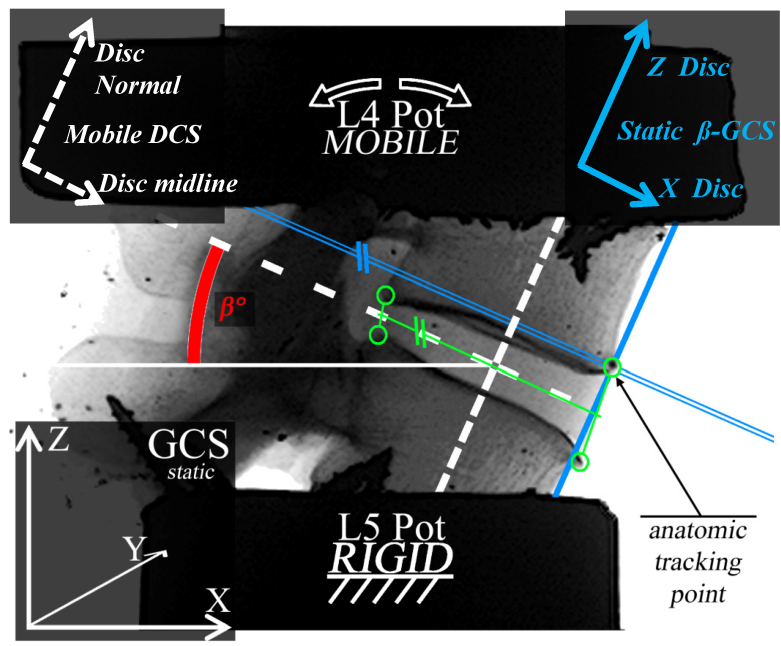

Fig. 1. Potted L4-L5 Specimen Parameters. Anterior and posterior corners of the cranial and caudal endplates (circled in green) were used to determine the midline of the intervertebral disc with inclination angle $\beta$ to the global coordinate system (GCS) horizontal. A moving disc coordinate system (DCS) was used to establish the dynamic orientation of the midline of the intervertebral disc during testing. Anterior-posterior and cranial-caudal displacements of the anterior corner of the $L 4$ endplate were determined within a fixed global coordinate system ( $\beta$-GCS) aligned with the midline of the intervertebral disc and with origin at the $L 4$ endplate corner under zero load conditions. 
ed PM and FL capabilities. ${ }^{23,31}$ The CLTS is a custom built 6-degree of freedom (DOF) system with robotic control and six-axis force-moment-sensor (FMS) (Model 45E15A4, JR3, 100lb capacity) (Figure 2). To incorporate shear forces the TW loading protocol was developed and applied in the current study. All force and moment loads were continuously applied for the PM, FL and TW loading protocols which are schematically illustrated in Figure 3. For all protocols moment loads were applied by the appropriate (yaxis) rotary gimbal motor operating in position control while the remaining 5 -axes were simultaneously load-controlled to targeted values (e.g. $0 \mathrm{~N}$ and $0 \mathrm{Nm}$ for PM loading (Figure 3A)).

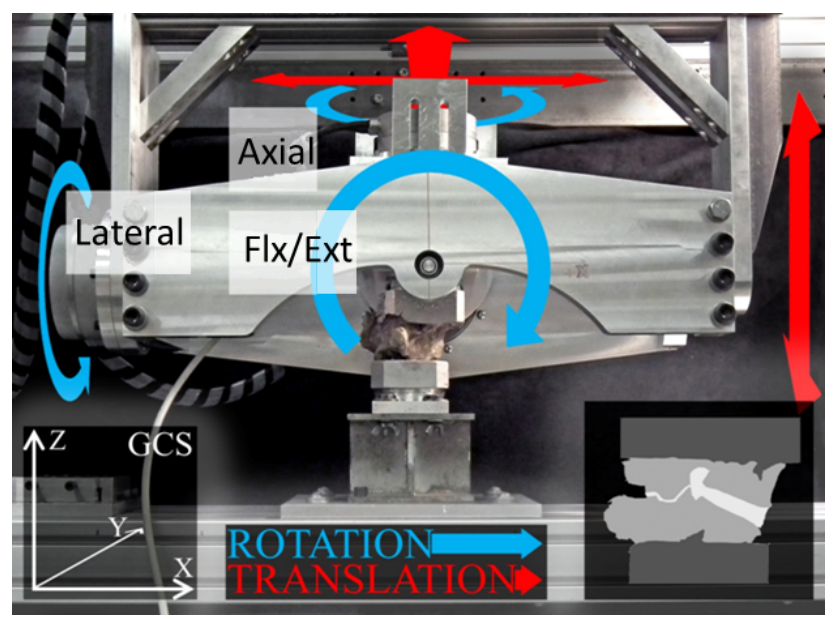

Fig. 2. Robotic Cartesian Biomechanical Testing System with L4-L5 Specimen. Three orthogonally oriented translational axes (red arrows) established a global Cartesian coordinate system (GCS) (left) with suspended gimbal comprised of three orthogonally oriented rotary motors (blue arrows). A six-axis force-moment sensor (FMS) was rigidly attached between the mobile end of the gantry system and cranial surface of the L4 specimen pot. All loads were commanded and controlled within a local moving force-moment sensor coordinate system (FMS-CS) the orientation of which was determined by the position of the gimbal motors.
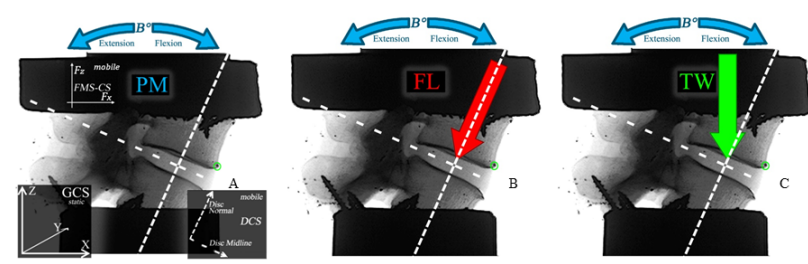

Fig. 3. Schematic Illustration of Applied Load Conditions. The loading conditions applied to each test specimen in the current study were A) sagittal plane pure moments (PM); B) simulated follower load (FL) protocol comprised of a $400 \mathrm{~N}$ force maintained in a direction normal to the midline of the intervertebral disc in combination with sagittal plane pure moments;

C) a novel trunk weight (TW) loading protocol comprised of constant vertically oriented $400 \mathrm{~N}$ force in combination with sagittal plane pure moments. A) also illustrates the initial orientations of the force-moment sensor (FMS-CS) and disc (DCS) coordinate systems.
The ideal FL vector is applied perpendicular to the mid-plane of the disc (Figure 3B). ${ }^{27,32}$ During sagittal bending the mid-plane of the disc rotates half as much as the cranial body requiring the load vector to change direction while maintaining constant resultant magnitude. Additionally the force-moment sensor and its (mobile) coordinate system was affixed to, and rotated with, the testing frame actuators. Therefore, at $0.2^{\circ}$ increments of position controlled sagittal rotation $F_{x}$ and $F_{z}$ forces in the FMS coordinate system (FMS-CS) were dynamically commanded as:

$F_{X}=400 \sin (B / 2-\beta)$

$F_{Z}=400 \cos (B / 2-\beta)$

where $B$ was the current sagittal plane rotation angle, and $\beta$ the neutral angle of the disc mid-plane (Figure 1). A common FL magnitude of $400 \mathrm{~N}$ was chosen for simulation. ${ }^{33-35}$ Linear Y-axis, and lateral and axial rotation axes were controlled to $0 \mathrm{~N}$ and $0 \mathrm{Nm}$, respectively.

The TW loading protocol applied a force that remained in a vertical orientation regardless of MSU movements simulating gravitational loading due to upper body segments referred to as 'trunk' weight for simplicity (Figure 3C). The protocol induced a shear force component along the midline of the disc and a compressive force component normal to the midline, the magnitudes of which depended on the midline inclination angle $(\beta)$. Since the force moment sensor rotated with the CLTS actuators, maintenance of a constant vertical resultant force during flexion-extension rotation also required dynamic application of $F_{x}$ and $F_{z}$ force components in the moving FMS-CS. For a $400 \mathrm{~N}$ trunk weight $F_{x}$ and $F_{z}$ forces in the FMS-CS were programmed at $0.2^{\circ}$ increments of sagittal rotation as:

$F_{X}=400 \sin (\beta)$

$F_{Z}=400 \cos (\beta)$

All tests were performed at a constant sagittal plane rotation rate of $0.35 \%$ sec. 


\section{D Kinematic Assessment}

To evaluate kinematic displacements between moving L4 and fixed L5 vertebral bodies an anatomic tracking point was chosen at the anterior corner of the L4 endplate. A rigid connection between the L4 vertebral body and the testing frame fixtures and tool tip was assumed. Sagittal plane $x$-ray images were taken to reference the known location of the CLTS tool tip to the chosen tracking point. Recorded CLTS tool tip displacements in the test frame global coordinate system were transformed to a fixed disc-oriented coordinate system ( $\beta$-GCS) with origin at the anterior L4 endplate corner and axes aligned with the midline of the disc and its normal in the zero load state (Figure 1). This stationary $\beta-G C S$ was chosen as a new reference frame for reporting displacements of the L4 endplate corner in a clinically relevant manner wherein we define cranial-caudal (CC) as normal to the disc midline and anterior posterior (AP) as along the disc midline.

Pixel resolution of images used to identify the tracking point, the system tool tip and their relative distance was $0.2 \mathrm{~mm}$. During testing actuator displacements used to calculate relative changes in the anatomic tracking point location had the following resolutions: $\pm 6.35 \mu \mathrm{m}$ for global $\mathrm{X}$ and $\mathrm{Z}$ axis directions and 0.00034 degrees for sagittal plane rotations. Thus while the absolute tracking point locations were determined with sub millimeter accuracy, relative movements were determined with much higher accuracy.

\section{Specimen Test Regiment}

Specimens were caudally fixed, cranially attached to the FMS and Cartesian manipulator, and placed in a zero-load state (neutral unloaded position). To ensure applied forces did not build up artifact moments a $400 \mathrm{~N}$ FL vector was applied by sequentially applying $F_{z}$ and $F_{x}$ component forces while constraining flexion-extension rotation. Observed sagittal moment values in this state were due to offset of net reactive specimen forces with respect to the default FMS reference frame. The FMS reference frame was transformed in the $\mathrm{x}$ - and $\mathrm{z}$-directions to null these values. In the neutral starting orientation application of a FL vertical $F_{z}$ force component was the same as applying a TW force with slightly smaller magnitude. As such, the relocated FMS reference frame from the above procedure was observed to null artifact sagittal moments for the TW protocol as well. Moment values were determined with respect to this newly located FMS reference frame for all tests.

For PM tests, tissue was preconditioned by applying $8.5 \mathrm{Nm}$ pure flexion-extension moments for three cycles with data analyzed for the third cycle. For FL and TW protocols $F_{z}$ and $F_{x}$ force components were applied in a loaded neutral position for 3 seconds. The loaded specimen was subsequently extended and flexed three times to an $8.5 \mathrm{Nm}$ end-limit with data analyzed for the third cycle. Specimens were sequentially tested under FL, TW, and PM protocols. Specimens were loosely wrapped in moistened cloth to prevent dehydration.

\section{Data Collection and Processing}

Rotational and translational displacements, force and moment data were recorded at $10 \mathrm{~Hz}$. RROM and anatomic tracking point displacements were determined and compared under no load, neutrally loaded, $8 \mathrm{Nm}$ flexed and $8 \mathrm{Nm}$ extended conditions. Observed $F_{z}$ and $F_{x}$ component forces were combined and resolved along the vertical for the TW protocol and normal to the midline of the intervertebral disc for the FL protocol to determine applied resultant force values. Absolute mean load tracking errors (TE), (difference between ideal programmed and experimentally achieved loads) were computed throughout the range of motion for each test to determine the tolerance within which applied loads were held.

Flexibility and neutral zone (NZ) parameters were determined using a method similar to that of Smit et al. ${ }^{36}$ Flexibility curves were segmented into three load regions: $4 \mathrm{Nm}$ to $8.5 \mathrm{Nm}$ in extension, $4 \mathrm{Nm}$ extension to $4 \mathrm{Nm}$ flexion (transition region), and $4 \mathrm{Nm}$ to $8.5 \mathrm{Nm}$ in flexion. Curve segments representing increasing bending moment application in flexion and in extension, as well as the transition region from extension to flexion, were fitted with sixth order polynomial equations with coefficients to 8 decimal places (average linear regression fit of 0.999 (Microsoft Excel 2010)). The first derivative of each equation was evaluated in the transition region to

Downloaded from http://ijssurgery.com/ by guest on April 26, 2023 
find the maximum slope (hence maximum flexibility) in the NZ, and at $8 \mathrm{Nm}$ of flexion and extension to determine flexibility. The values of maximum slopes were recorded for statistical comparison between the three load conditions. For NZ characterization, maximum and minimum values of the second derivative of the fitted polynomial curves in the transition region identified the points of greatest rate of change in flexibility and hence the 'heel' points marking the transition from the centralized NZ (high flexibility) to the elastic zone (low flexibility). NZ range of motion was then determined as the degrees of rotation occurring between the heel points of the curve.

\section{Statistical Methods}

All data sets were tested using the Shapiro-Wilk test and determined to be normally distributed.

Repeated-measures analyses of variance were used to discern differences across protocols in RROM, translational and flexibility data. Where differences existed, Bonferroni post hoc comparisons were used to discern pair wise statistically significant differences $(\mathrm{p}<0.05)$.

\section{Results}

The mean value of the disc angle $\beta$ was $25^{\circ}$ (range $18^{\circ}$ to $37^{\circ}$ ) for the six MSU segments. These values corresponded to average shear components of $172 \mathrm{~N}$ (range $158 \mathrm{~N}$ to $186 \mathrm{~N}$ ) and compressive components of $359 \mathrm{~N}$ (range $350 \mathrm{~N}$ to $371 \mathrm{~N}$ ) across the L4-L5 intervertebral disc with application of TW loading.

\section{Load Control Tolerance}

Load-controlled axes were generally held within $3 \mathrm{~N}$ or $0.05 \mathrm{Nm}$ of their respective targets with maximum absolute TEs of $15 \mathrm{~N}$ and $0.1 \mathrm{Nm}$, respectively. Mean absolute TEs for resolved force vectors $\left(F_{\text {Res }}\right)$ in the $\mathrm{FL}$ and $\mathrm{TW}$ protocols were $1.3 \mathrm{~N}$ (standard deviation (SD) 1.6), and 1.3N (SD 1.4), respectively. Maximum force TE's occurred during direction reversals (at $8.5 \mathrm{Nm}$ ) and hence outside the end limits of analysis.

\section{Rotational Range of Motion}

Mean RROM values at $8 \mathrm{Nm}$ flexion for PM, FL, and TW protocols were not statistically different with values of $5.16^{\circ}\left(\mathrm{SD} 1.45^{\circ}\right), 5.01^{\circ}\left(\mathrm{SD} 1.70^{\circ}\right)$, and $4.78^{\circ}\left(\mathrm{SD} 1.78^{\circ}\right)$, respectively. RROM values at $8 \mathrm{Nm}$ extension for the same protocols were also not statistically different with values of $3.02^{\circ}\left(\mathrm{SD} 1.11^{\circ}\right), 2.60^{\circ}$ $\left(\mathrm{SD} 1.16^{\circ}\right)$, and $2.58^{\circ}\left(\mathrm{SD} 1.01^{\circ}\right)$, respectively. When flexion and extension rotations were combined the TW protocol demonstrated significantly less total RROM as compared to the PM tests $(\mathrm{p}=0.027)$.

\section{Flexibility and Neutral Zone Range of Motion}

Figure 4 shows example moment-angle flexibility graphs demonstrating typical hysteresis profiles. Mean flexibility values determined at $8 \mathrm{Nm}$ of bending in extension were $0.21^{\circ} / \mathrm{Nm}$ (SD 0.07), $0.17^{\circ} / \mathrm{Nm}(\mathrm{SD} 0.06)$ and $0.16^{\circ} / \mathrm{Nm}$ (SD 0.06) for the PM, FL and TW protocols respectively. The FL demonstrated a borderline difference $(p=0.048)$, and TW loading a significant difference $(\mathrm{p}=0.03)$ compared to flexibility for PM loading in extension. Mean values of $0.25^{\circ} / \mathrm{Nm}$ (SD 0.07), $0.31^{\circ} / \mathrm{Nm}$ (SD $0.08)$ and $0.28^{\circ} / \mathrm{Nm}(\mathrm{SD} 0.07)$ at $8 \mathrm{Nm}$ flexion for the PM, FL, and TW protocols respectively, were not significantly different $(\mathrm{p}=.38)$. Average peak NZ flexibility values were determined to be $1.93^{\circ} / \mathrm{Nm}$ (SD 1.11), $1.18^{\circ} / \mathrm{Nm}(\mathrm{SD} 0.54)$ and $1.02^{\circ} / \mathrm{Nm}$ (SD $0.5)$ for PM, FL and TW protocols respectively. A significant difference $(\mathrm{p}=0.037)$ occurred between the PM and TW protocols. Computation of NZ RROM yielded mean values of $3.22^{\circ}$ (SD 1.04), 3.66 (SD 1.06), and $3.56^{\circ}$ (SD 1.08) that were not significantly different $(\mathrm{p}=.83)$ for the same three protocols respectively.

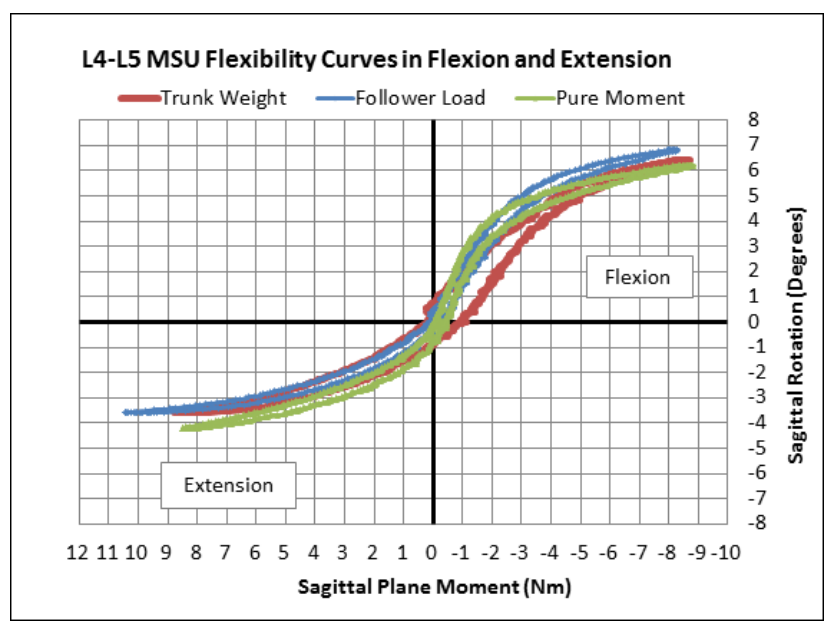

Fig. 4. Flexibility Curves for Single Test Specimen. Flexibility profiles for a single specimen tested under pure moment, follower load and trunk weight loading protocols. All three protocols exhibited typical non-linear hysteresis characteristics. 
L4 Vertebral Body Displacements

Absolute anatomic tracking point displacements with initial force application and subsequent applied bending are shown in Figure 5, and with statistically significant differences indicated in Table 1 . Near significant differences are noted as well. Under initial FL and TW force applications (prior to flexionextension bending) sagittal plane rotation was held fixed. Anatomic point displacements thus reflected pure mean L4 body translations. Mean L4 translations normal to the midline of the intervertebral disc were significantly increased with both FL and TW load application $(0.6 \mathrm{~mm}$ (SD 0.2) caudal and $0.4 \mathrm{~mm}$ (SD 0.2) caudal respectively). FL application resulted in a mean posterior $\mathrm{L} 4$ translation $(0.2 \mathrm{~mm}$ (SD 0.3 ) while TW load application produced a significant mean anterior translation (1.1mm (SD 0.7)).

In full extension mean AP tracking point displacements were significantly smaller with the TW protocol (0.25mm anterior (SD 0.9)) as compared to the FL protocol (1.0mm posterior (SD 0.6) and the PM protocol $(0.8 \mathrm{~mm}$ posterior (SD 0.4)). Cranial-caudal tracking point displacement was significantly greater with the PM protocol in extension (1.2mm (SD 0.5) compared to both FL (0.6mm (SD0.4)) and TW $(0.7 \mathrm{~mm}(\mathrm{SD} 0.3))$ tests.

In full flexion mean anterior displacements were significantly different in the TW protocol $(2.5 \mathrm{~mm}$ (SD $0.9)$ ) as compared to FL (0.9mm (SD 0.8) and PM protocols (1.3mm (SD 0.7)). CC displacements in flexion were only different between the PM $(2.0 \mathrm{~mm}$ caudal (SD 0.7)) and FL protocols (2.5mm caudal (SD 0.9)).

In contrast relative tracking point displacements between initial neutral force loaded positions, and fully extended or flexed positions, were not significantly different between the three tests. For the PM protocol mean displacements were $1.2 \mathrm{~mm}$ (SD 0.5) cranial and $0.8 \mathrm{~mm}$ (SD 0.4) posterior, and 2.0mm (SD 0.7) caudal and $1.3 \mathrm{~m}$ (SD 0.7) anterior in extension and flexion, respectively. Relative anatomic tracking point displacements in extension determined with respect to the initial neutral force loaded positions for FL and TW were $1.2 \mathrm{~mm}$ and $1.1 \mathrm{~mm}$ cranial, and $0.8 \mathrm{~mm}$ and $1.0 \mathrm{~mm}$ posterior translations, respectively. Rela- tive flexion tracking point displacements for FL and

\begin{tabular}{|c|c|c|c|c|c|}
\hline $\begin{array}{l}\text { Bending } \\
\text { Region }\end{array}$ & $\begin{array}{l}\text { Displacement } \\
\text { Direction }\end{array}$ & $\begin{array}{l}\text { Loading } \\
\text { Protocol }\end{array}$ & $\begin{array}{l}\text { Mean Dis- } \\
\text { placement } \\
(\mathbf{m m})\end{array}$ & SD & $\begin{array}{r}\text { Statistical } \\
\text { Differences }\end{array}$ \\
\hline \multirow{6}{*}{ Neutral1 } & & PM & 0.0 & $\begin{array}{r} \pm \\
0.0\end{array}$ & $\begin{array}{r}\text { TW: } \\
\mathrm{p}=0.005^{*}\end{array}$ \\
\hline & $\mathrm{AP}$ & $\mathrm{FL}$ & -0.2 & $\begin{array}{r} \pm \\
0.3\end{array}$ & $\begin{array}{r}\text { TW: } \\
\mathrm{p}=0.001^{*}\end{array}$ \\
\hline & & TW & 1.1 & $\begin{array}{r} \pm \\
0.7\end{array}$ & PM, FL \\
\hline & & PM & 0.0 & $\begin{array}{r} \pm \\
0.0\end{array}$ & $\begin{array}{r}\text { FL: } \\
\mathrm{p}<0.0001^{*}, \\
\mathrm{TW}: \\
\mathrm{p}=0.0001^{*}\end{array}$ \\
\hline & $\mathrm{CC}$ & $\mathrm{FL}$ & -0.6 & $\begin{array}{r} \pm \\
0.2\end{array}$ & $\begin{array}{r}\text { TW: } \\
\mathrm{p}=0.017^{*}\end{array}$ \\
\hline & & TW & -0.4 & $\begin{array}{r} \pm \\
0.2\end{array}$ & PM, FL \\
\hline \multirow{6}{*}{ Extension $_{2}$} & & PM & -0.8 & $\begin{array}{r} \pm \\
0.4\end{array}$ & $\begin{array}{r}\text { TW: } \\
\mathrm{p}=0.0008^{*}\end{array}$ \\
\hline & $\mathrm{AP}$ & $\mathrm{FL}$ & -1.0 & $\begin{array}{r} \pm \\
0.6\end{array}$ & $\begin{array}{r}\text { TW: } \\
\mathrm{p}=0.0003^{*}\end{array}$ \\
\hline & & TW & 0.3 & $\begin{array}{r} \pm \\
0.9\end{array}$ & PM, FL \\
\hline & & PM & 1.2 & $\begin{array}{r} \pm \\
0.5\end{array}$ & $\begin{array}{r}\text { FL: } \\
\mathrm{p}=0.0022^{*} \\
\mathrm{TW}: \\
\mathrm{p}=0.014^{*}\end{array}$ \\
\hline & $\mathrm{CC}$ & $\mathrm{FL}$ & 0.6 & $\begin{array}{r} \pm \\
0.4\end{array}$ & PM \\
\hline & & TW & 0.7 & $\begin{array}{r} \pm \\
0.3\end{array}$ & PM \\
\hline \multirow{6}{*}{ Flexion3 } & & PM & 1.3 & $\begin{array}{r} \pm \\
0.7\end{array}$ & $\begin{array}{r}\text { TW: } \\
\mathrm{p}=0.001^{*}\end{array}$ \\
\hline & AP & $\mathrm{FL}$ & 0.9 & $\begin{array}{r} \pm \\
0.8\end{array}$ & $\begin{array}{r}\text { TW: } \\
\mathrm{p}<0.0001^{*}\end{array}$ \\
\hline & & TW & 2.5 & $\begin{array}{r} \pm \\
0.9\end{array}$ & PM, FL \\
\hline & & PM & -2.0 & $\begin{array}{r} \pm \\
0.7\end{array}$ & $\begin{array}{r}\text { FL: } \\
\mathrm{p}=0.0052^{*}\end{array}$ \\
\hline & $\mathrm{CC}$ & $\mathrm{FL}$ & -2.5 & $\begin{array}{r} \pm \\
0.9\end{array}$ & PM \\
\hline & & TW & -2.3 & $\begin{array}{r} \pm \\
0.8\end{array}$ & FL: $\mathrm{p}=0.058$ \\
\hline
\end{tabular}

Mean anterior-posterior (AP) and cranial-caudal (CC) anatomic tracking point (anterior corner of the L4 end plate) displacements with respect to the $\beta$-global coordinate system are tabularized for each of the three loading protocols in the neutral ( $0 \mathrm{Nm}$ bending), fully extended $(8 \mathrm{Nm})$ and fully flexed $(8 \mathrm{Nm})$ positions. Significant differences are indicated in the last column. *Statistically significant $0.05 \mathrm{Cl}$. 
TW were $1.9 \mathrm{~mm}$ and $1.8 \mathrm{~mm}$ caudal, and $1.1 \mathrm{~mm}$ and $1.4 \mathrm{~mm}$ anterior, respectively.

\section{Discussion}

This initial investigation utilized a recently developed custom robotic $6 \mathrm{DOF}$ testing system with continuous real-time load application to implement standardized and unique in-vitro loading protocols for comparison without artifact due to different laboratory protocols or loading mechanisms. Translational displacements of the L4 vertebral with respect to L5 demonstrated significant differences between the three initial force loaded states that were consistent with and tended to directly follow the differences in applied forces. Relative to zero force application in the PM protocol, the FL induced the greatest compressive force normal to the disc resulting in the largest caudal L4 translations as well as a moderate amount of posterior displacement that may have been due to facet engagement. Smaller compressive force components across the disc with the TW protocol resulted in less CC displacement. However, the anterior directed shear force component along the midline of the disc with this protocol produced the largest mean translational (anterior) displacement between L4 and L5 observed due to applied force.

Relative anatomic tracking point displacement values

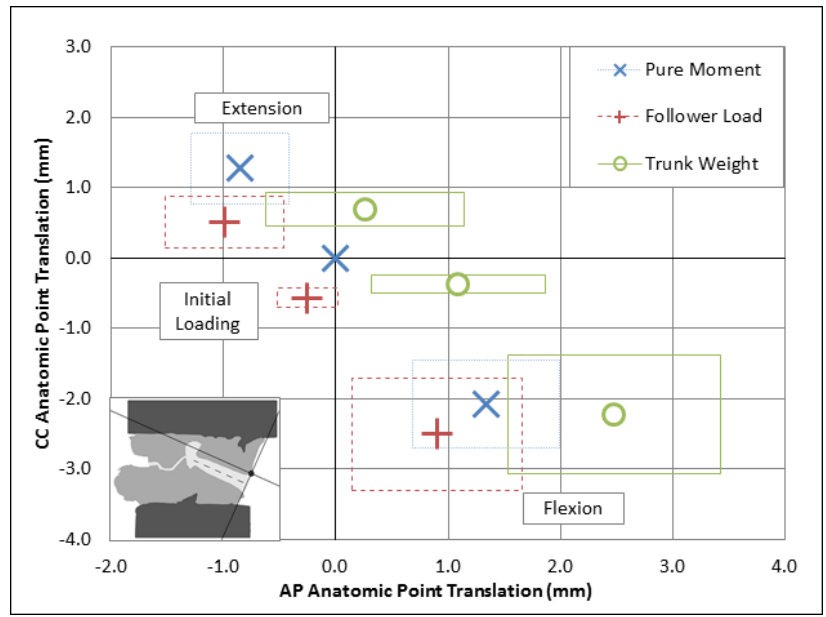

Fig. 5. Mean values of anterior-posterior (AP) (X axis) and cranial-caudal (CC) ( $Z$ axis) anatomic tracking point displacements in the $\beta$-Global Coordinate System are presented for the PM, FL and TW protocols in three groupings indicating values at $8 \mathrm{Nm}$ of extension (top-left quadrant), $0 \mathrm{Nm}$ neutral position (origin), and at $8 \mathrm{Nm}$ of flexion (bottom right quadrant).

Boxes represent one standard deviation from the mean value in both AP and CC directions. between initial force loaded FL and TW neutral positions, and fully flexed or extended positions following subsequent bending moment application, revealed no significant differences in CC and AP displacements between the protocols.

Few studies report vertebral body translations during bending tests. Most comparable to the current study Heuer et al..$^{37}$ reported mean displacements for the same tracking point and coordinate system for $8 \mathrm{hu}-$ man L4-L5 lumbar segments under 7.5Nm of pure bending. They reported displacement values of $1.3 \mathrm{~mm}$ cranial and $0.45 \mathrm{~mm}$ posterior in extension, and $2.1 \mathrm{~mm}$ caudal and $1.0 \mathrm{~mm}$ anterior in flexion. These values are in good agreement with the current study. Collectively, the above suggests that displacement offsets due to initial FL and TW force application were maintained through flexion-extension, and that relative tracking point displacements due to applied bending moments only were equivalent over the three different loading conditions.

No significant differences were found in the current study in flexion or extension RROM alone between the three different loading protocols. However, most studies compare combined flexion-extension rotations. In combined flexion-extension PM and FL RROM data from the current study were consistent with those from non-robotic studies. ${ }^{33,34,38-40} \mathrm{We}$ observed a trend of decreasing RROM from PM to FL similar to that observed by O'Leary et al. ${ }^{33}$ and Niosi et al. ${ }^{38}$ (Figure 6). Minor differences in segmental rotation were previously reported by Rohlmann et al. ${ }^{41}$ with a FL magnitude of $280 \mathrm{~N}$ as compared to a PM protocol. Patwardhan et al. ${ }^{32}$ observed the above trend and concluded that RROM was significantly affected by FL magnitude beginning at $400 \mathrm{~N}$. In contrast the current study did observe a significantly reduced RROM in combined flexion-extension for the TW protocol as compared to PM application. This preliminary result points towards a stabilizing effect with application of an anteriorly directed shear force. Possible mechanisms for this observation include increased facet contact and guidance as well as increased ligament strain with observed anterior displacement.

Flexibility values were quantitatively determined 
from the first derivative (i.e. the slope) of sixth order polynomial functions fitted to moment rotation curves. Although a single curve fit through the entire flexion-extension range of motion provided what appeared to be a reasonable correlation of fit, closer inspection revealed that the fitted profile could deviate from the curvature of the actual data set enough to significantly impact the slope in a particular region. It was thus necessary to break the flexibility curve into regions of interest, increase the polynomial order to six, and to accurately prescribe polynomial coefficients with up to 8 decimal places so as to maintain a minimum correlation of fit of 0.993 .

Mean flexibility values computed at $8 \mathrm{Nm}$ of flexion were not statistically different between the three protocols tested. Mean flexibility values at $8 \mathrm{Nm}$ of extension were borderline and significantly reduced with the FL ( $\mathrm{p}=0.048)$ and TW $(\mathrm{p}=0.03)$ protocols respectively, compared to the PM protocol. This result is consistent with our observed trend of reduced RROM with the FL versus the PM protocol, and a significantly reduced RROM with the TW protocol as compared to the PM protocol. Similarly, average peak flexibility values computed through the NZ region demonstrated a trend for reduction in value with FL application ( $\mathrm{p}=0.09)$ and a significant reduction with TW application $(\mathrm{p}=0.037)$ as compared to PM loading. Collectively these results further support a quantitatively small but significant stabilizing

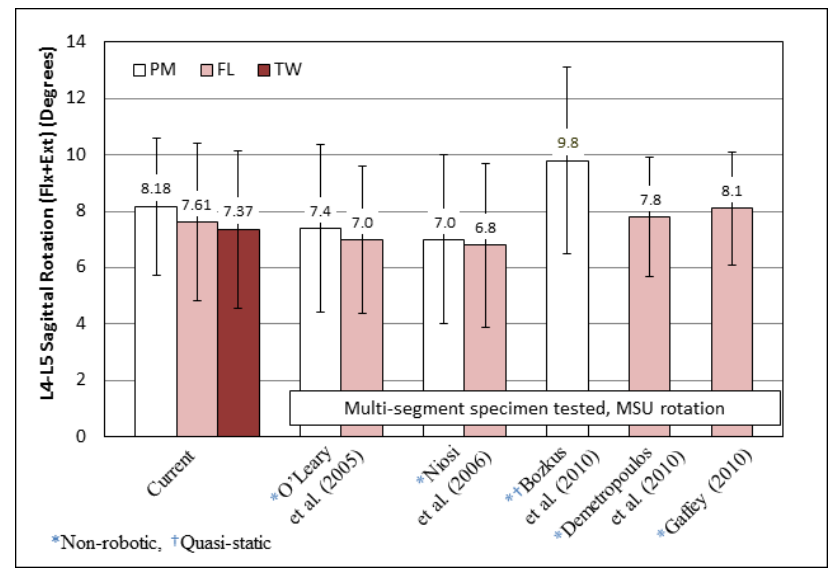

Fig. 6. Combined Sagittal Rotational Range of Motion Literature

Comparison. Mean sagittal plane L4-L5 MSU rotational ranges of motion in flexion and extension were combined for presentation and comparison with previously published values of combined L4-L5 ranges of motion. Differences between studies such as single versus multi-segment specimens, non-robotic versus robotic and continuous versus quasi-static loading methods are noted. effect with combined compression and shear force application that may be most pronounced through the neutral zone region and in extension. Analysis of NZ-ROM did not reveal any differences between the three different loading protocols.

Previous robotic methodologies applied to in-vitro biomechanical testing of the spine have focused on PM application only, and have been primarily limited to quasi-static, iterative, and/or position control approaches. ${ }^{18,22,42-44}$ In the current study the TW protocol that was developed expanded on the coordinated dynamic force vector application capability of the CLTS. Z-axis and $\mathrm{x}$-axis forces in the local FMS-CS were modulated to maintain a vertical resultant $400 \mathrm{~N}$ load at L4 through full flexion-extension ranges of motion inducing compression and shear forces across the inclined spinal joint in combination with sagittal plane bending.

Off-axis zero commanded force and moment loads demonstrated absolute mean TE's of $0.70 \mathrm{~N}$ and $0.03 \mathrm{Nm}$ respectively. For the FL and TW protocols absolute mean TE's of $1.28 \mathrm{~N}$ (SD 1.55) and 1.34N (SD 1.40) observed for resultant applied forces $\left(F_{R e s}\right)$ represented less than $0.8 \%$ of the targeted $400 \mathrm{~N}$ value within a $8 \mathrm{Nm}$ bending range. These data indicate that the intended loading protocols were applied to within a small tolerance.

A few previous biomechanical studies have investigated combined compression and shear on intact and instrumented spine segments but with flexionextension rotation angles held fixed. ${ }^{6,45}$ Augmentation of current standardized in-vitro testing protocols to simultaneously include a shear component may be a useful tool in cases where a substantial amount of shear is thought to exist. Inclusion of shear may contribute significantly towards investigations of clinical conditions such as spinal stenosis and spondylolisthesis, as well as the stabilizing performance and load sharing characteristics of different types of spinal instrumentation.

\section{Limitations}

Results of this study were limited to relatively young, male L4-L5 MSUs with no radiographically evident degenerative changes. Current results reflect the in- 
tact test specimen condition only. Destabilized and/ or surgically altered spine conditions may produce different outcomes. Testing protocols were not randomized but sequentially applied. All tests and analyses were confined to the sagittal plane. Shear forces induced during the TW protocol were a direct result of potted MSU alignment (targeted as neutral) and inherent disc angle. The small sample size used in the study limited statistical power and increased potential for a type II error.

Proposed future application and development should include non-sagittal analyses. In the current study specimen specific alignment with TW application was intended to reflect the in-vivo condition and subject variability however, for future work a standardized potting angle and/or shear force application is recommended. Lastly, the extent to which the protocols used herein may be more broadly applied to spinal segments with more than one motion segment unit remains to be determined in future work.

\section{Conclusion}

A 6DOF Cartesian load controlled testing system was used to biomechanically compare the influence of a pure moment, follower load, and a vertically oriented trunk weight loading protocol designed to include shear forces on human cadaveric L4-L5 MSU's through full physiologic flexion-extension ranges of motion. Significant differences in sagittal plane translations were observed with the different initial force applications but not with subsequent applied bending moments between the three protocols. Significant reductions were observed in combined flexion-extension RROM, in flexibility during extension, and in NZ region flexibility with the TW loading protocol as compared to PM loading. Combined compression and shear forces applied across the spinal joint in the TW protocol may have a small but significantly increased stabilizing effect on segment flexibility and kinematics during sagittal plane flexion and extension.

\section{References}

1. Patwardhan AG, Havey RM, Meade KP, Lee B,
Dunlap B. A follower load increases the loadcarrying capacity of the lumbar spine in compression. Spine. 1999 May 15;24(10):1003-9.

2. Panjabi MM. Biomechanical evaluation of spinal fixation devices: I. A conceptual framework. Spine. 1988 Oct;13(10):1129-34.

3. Adams MA, Bogduk N, Burton K, Dolan P. The Biomechanics of Back Pain: Elsevier Science Ltd. ; 2002.

4. White AA, III, Panjabi MM. Clinical Biomechanics of the Spine. 2nd Edition ed. Philadelphia, PA: Lippincott; 1990.

5. Kingma I, Staudenmann D, van Dieen JH. Trunk muscle activation and associated lumbar spine joint shear forces under different levels of external forward force applied to the trunk. Journal of electromyography and kinesiology : official journal of the International Society of Electrophysiological Kinesiology. 2007 Feb;17(1):14-24.

6. Rousseau MA, Bradford DS, Bertagnoli R, Hu SS, Lotz JC. Disc arthroplasty design influences intervertebral kinematics and facet forces. Spine J. 2006 May-Jun;6(3):258-66.

7. Melnyk AD, Wen TL, Kingwell S, Chak JD, Singh V, Cripton PA, et al. Load transfer characteristics between posterior spinal implants and the lumbar spine under anterior shear loading: an in vitro investigation. Spine. 2012 Aug 15;37(18):E1126-33.

8. Vicars R, Prokopovich P, Brown TD, Tipper JL, Ingham E, Fisher J, et al. The effect of anteriorposterior shear on the wear of CHARITE total disc replacement. Spine (Phila Pa 1976). 2012 Apr 20;37(9):E528-34.

9. Kubo S, Goel VK, Yang SJ, Tajima N. Biomechanical evaluation of cervical double-door laminoplasty using hydroxyapatite spacer. Spine. $2003 \mathrm{Feb}$ 1;28(3):227-34.

10. Miura T, Panjabi MM, Cripton PA. A method to simulate in vivo cervical spine kinematics using in vitro compressive preload. Spine. 2002 Jan 1;27(1):43-8.

11. Dickey JP, Kerr DJ. Effect of specimen length: are the mechanics of individual motion segments comparable in functional spinal units and multisegment specimens? Med Eng Phys. 2003;25(3):221-7. 12. Crawford NR, Brantley AG, Dickman CA, Koeneman EJ. An apparatus for applying pure non- 
constraining moments to spine segments in vitro. Spine (Phila Pa 1976). 1995 Oct 1;20(19):2097-100. 13. DiAngelo DJ, Foley KT. An improved biomechanical testing protocol for evaluating spinal arthroplasty and motion preservation devices in a multilevel human cadaveric cervical model. Neurosurg Focus. 2004 Sep 15;17(3):E4.

14. Yoganandan N, Cusick JF, Pintar FA, Droese K, Reinartz J. Cyclic compression-flexion loading of the human lumbar spine. Spine (Phila Pa 1976). [Research Support, U.S. Gov't, Non-P.H.S.]. 1994 Apr 1;19(7):784-90; discussion 91.

15. Kikkawa J, Cunningham BW, Shirado O, Hu N, McAfee PC, Oda H. Biomechanical evaluation of a posterolateral lumbar disc arthroplasty device: an in vitro human cadaveric model. Spine (Phila Pa 1976). 2010 Sep 1;35(19):1760-8.

16. Kunz DN, Mccabe RP, Zdeblick TA, Vanderby R. A Multi-Degree-of-Freedom System for Biomechanical Testing. J Biomech Eng-T Asme. 1994

Aug;116(3):371-3.

17. Goertzen DJ, Kawchuk GN. A novel application of velocity-based force control for use in robotic biomechanical testing. J Biomech. 2009 Feb 9;42(3):366-9.

18. Walker MR, Dickey JP. New methodology for multi-dimensional spinal joint testing with a parallel robot. Med Biol Eng Comput. 2007

Mar;45(3):297-304.

19. Thompson RE, Barker TM, Pearcy MJ. Defining the Neutral Zone of sheep intervertebral joints during dynamic motions: an in vitro study. Clin Biomech (Bristol, Avon). 2003 Feb;18(2):89-98.

20. Gilbertson LG, Doehring TC, Kang JD. New Methods to Study Lumbar Spine Biomechanics: Delineation of In-Vitro Load-Displacement Characteristics by Using a Robotic/UFS Testing System with Hybrid Control. Operative Techniques in Orthopedics. 2000;10(4):246-53.

21. Schulze M, Hartensuer R, Gehweiler D, Holscher U, Raschke MJ, Vordemvenne T. Evaluation of a robot-assisted testing system for multisegmental spine specimens. J Biomech. 2012 May 11;45(8):1457-62.

22. Kelly BP, DiAngelo DJ. A Multi-Axis Programmable Robot for the Study of Multi-Body Spine Biomechanics Using Real-Time Trajectory Path Modifi- cation Force and Displacement Control Strategies. ASME Journal of Medical Devices. [Technical Note]. 2013 Jul 03;7(3):7 pages.

23. Kelly BP, Bennett CR. Design and validation of a novel Cartesian biomechanical testing system with coordinated 6DOF real-time load control: application to the lumbar spine (L1-S, L4-L5). J Biomech. 2013 Jul 26;46(11):1948-54.

24. Eguizabal J, Tufaga M, Scheer JK, Ames C, Lotz JC, Buckley JM. Pure moment testing for spinal biomechanics applications: Fixed versus sliding ring cable-driven test designs. J Biomech. 2010 May 7;43(7):1422-5.

25. Wheeler DJ, Freeman AL, Ellingson AM, Nuckley DJ, Buckley JM, Scheer JK, et al. Interlaboratory variability in in vitro spinal segment flexibility testing. J Biomech. 2011 Sep 2;44(13):2383-7.

26. Patwardhan AG, Havey RM, Carandang G, Simonds J, Voronov LI, Ghanayem AJ, et al. Effect of compressive follower preload on the flexion-

extension response of the human lumbar spine. J Orthop Res. 2003 May;21(3):540-6.

27. Cripton PA, Bruehlmann SB, Orr TE, Oxland

TR, Nolte LP. In vitro axial preload application during spine flexibility testing: towards reduced apparatus-related artefacts. J Biomech. 2000 Dec;33(12):1559-68.

28. Janevic J, Ashton-Miller JA, Schultz AB. Large compressive preloads decrease lumbar motion segment flexibility. J Orthop Res. 1991 Mar;9(2):228-36. 29. Miller JA, Skogland LB. On the loaddisplacement behaviour of adolescent spinal motion segments - an experimental study using autopsy specimens. Oslo, Norway: University of Oslo; 1980. 30. Panjabi MM, Krag MH, White AA, 3rd, Southwick WO. Effects of preload on load displacement curves of the lumbar spine. Orthop Clin North Am. 1977 Jan;8(1):181-92.

31. Bennett CR, Kelly BP. Robotic application of a dynamic resultant force vector using real-time loadcontrol: simulation of an ideal follower load on Cadaveric L4-L5 segments. J Biomech. 2013 Aug 9;46(12):2087-92.

32. Patwardhan AG, Havey RM, Carandang G, Simonds J, Voronov LI, Ghanayem AJ, et al. Effect of compressive follower preload on the flex-

ion-extension response of the human lumbar spine. 
Journal of Orthopaedic Research. 2003;21(3):540-6. 33. O'Leary P, Nicolakis M, Lorenz MA, Voronov LI, Zindrick MR, Ghanayem A, et al. Response of Charite total disc replacement under physiologic loads: prosthesis component motion patterns. Spine J. 2005 Nov-Dec;5(6):590-9.

34. Gaffey JL, Ghanayem AJ, Voronov ML, Havey RM, Carandang G, Abjornson C, et al. Effect of increasing implant height on lumbar spine kinematics and foraminal size using the ProDisc-L prosthesis. Spine (Phila Pa 1976). 2010 Sep 1;35(19):1777-82. 35. Renner SM, Tsitsopoulos PP, Dimitriadis AT, Voronov LI, Havey RM, Carandang G, et al. Restoration of spinal alignment and disk mechanics following polyetheretherketone wafer kyphoplasty with StaXx FX. AJNR Am J Neuroradiol. 2011 Aug;32(7):1295-300.

36. Smit TH, van Tunen MS, van der Veen AJ, Kingma I, van Dieen JH. Quantifying intervertebral disc mechanics: a new definition of the neutral zone. BMC musculoskeletal disorders. 2011;12:38.

37. Heuer F, Schmidt H, Claes L, Wilke HJ. Stepwise reduction of functional spinal structures increase vertebral translation and intradiscal pressure. J Biomech. 2007;40(4):795-803.

38. Niosi CA, Zhu QA, Wilson DC, Keynan O, Wilson DR, Oxland TR. Biomechanical characterization of the three-dimensional kinematic behaviour of the Dynesys dynamic stabilization system: an in vitro study. European spine journal : official publication of the European Spine Society, the European Spinal Deformity Society, and the European Section of the Cervical Spine Research Society. 2006 Jun;15(6):913-22.

39. Bozkus H, Senoglu M, Baek S, Sawa AG, Ozer AF, Sonntag VK, et al. Dynamic lumbar pedicle screw-rod stabilization: in vitro biomechanical comparison with standard rigid pedicle screw-rod stabilization. Journal of neurosurgery Spine. 2010 Feb;12(2):183-9.

40. Demetropoulos CK, Sengupta DK, Knaub MA, Wiater BP, Abjornson C, Truumees E, et al. Biomechanical evaluation of the kinematics of the cadaver lumbar spine following disc replacement with the ProDisc-L prosthesis. Spine (Phila Pa 1976). 2010 Jan 1;35(1):26-31.

41. Rohlmann A, Neller S, Claes L, Bergmann G, Wilke HJ. Influence of a follower load on intradiscal pressure and intersegmental rotation of the lumbar spine. Spine (Phila Pa 1976). 2001 Dec 15;26(24):E557-61.

42. Dickey JP, Gillespie KA. Representation of passive spinal element contributions to in vitro flexionextension using a polynomial model: illustration using the porcine lumbar spine. J Biomech. 2003 Jun;36(6):883-8.

43. Gardner-Morse MG, Stokes IA. Structural behavior of human lumbar spinal motion segments. J Biomech. [Research Support, U.S. Gov't, P.H.S.]. 2004 Feb;37(2):205-12.

44. Thompson RE, Barker TM, Pearcy MJ. Defining the Neutral Zone of sheep intervertebral joints during dynamic motions: an in vitro study. Clinical biomechanics. $2003 \mathrm{Feb}$;18(2):89-98.

45. Melnyk AD, Chak JD, Cripton PA, Dvorak MF, Oxland TR. Shear force measurements on low- and high-stiffness posterior fusion devices. Medical engineering \& physics. 2012 Nov;34(9):1260-7.

\section{Disclosures}

The authors declare no relevant financial disclosures.

\section{Corresponding Author}

Brian P. Kelly PhD, Division of Neurological Surgery, Barrow Neurological Institute, 350 West Thomas Rd, Phoenix, AZ, 85013. brian.kelly@dignityhealth.org.

Published 17 July 2015.

This manuscript is generously published free of charge by ISASS, the International Society for the Advancement of Spine Surgery. Copyright @ 2015 ISASS. To see more or order reprints or permissions, see http://ijssurgery.com. 